\title{
El cine en la formación inicial del docente
} The Cinema in the Teacher's Initial Training

\author{
Joaquín Giró Miranda'
}

\section{Resumen}

Este artículo se centra en el cine como herramienta de análisis práctico en la formación inicial del docente. El cine se sirve de la imaginación, las emociones y la cultura proponiendo otros modos de entender la vida social. Este texto, a través de la reflexión y el análisis de dos películas, intenta mostrar las posibilidades de un aprendizaje comprensivo del hecho de ser un buen docente, máxime cuando las prácticas del máster de secundaria o de los grados de maestro, apenas permiten acercarse a la realidad de lo que significa ser un buen docente.

\section{Palabras clave}

Cine, formación inicial, docente, emociones, empatía, socialización.

\section{Abstract}

This article focuses on cinema as a tool for practical analysis in the teacher's initial training. Cinema is used in imagination, emotions and culture, proposing other ways of understanding social life. This text, through the reflection and analysis of two films, tries to show the possibilities of a comprehensive learning of the fact of being a good teacher, especially when the practices of the Master of Secondary or the degrees of teacher, they can barely get close to the reality of what it means to be a good teacher.

\section{Keywords}

Film, initial training, teaching, emotions, empathy, socialization 


\section{Introducción: ¿̨Por qué el cine?}

El dominio de la imagen y la cultura audiovisual es innegable. Solo en Google aparecen 164000 videos que responden a la búsqueda de «cine y educación», un número suficiente como para entender que las nuevas tecnologías y la imagen acaparan el mundo educativo por encima de la lecto-escritura y, sin embargo, todavía se toma la tecnología audiovisual como un recurso docente o una herramienta al servicio del profesor, no constituyendo parte del currículo en la formación inicial del docente e interviniendo tan solo de manera transversal. Beltrán (2006: 88), señalaba que en sus clases «ha ensayado la integración de algunos contenidos y narraciones fílmicas como forma de ilustrar. En este caso la mirada sociológica deja de ser un término metafórico y se convierte en una descripción literal de un curso de acción educativa»; es decir, las acciones cinematográficas pasan por el filtro de la reflexión crítica para construir conocimiento científico, si bien este ejemplo es un caso aislado y no puede ser considerado como determinante en la formación inicial del docente.

En la formación inicial del docente, pese a los avances realizados en su transformación mediante grados y máster, todavía resulta escasa su práctica profesional, lo cual desemboca en un conocimiento muy básico sobre esta profesión y el significado de lo que se considera un buen docente. Porque, ¿qué es ser un buen docente? No se sabe con certidumbre, tan solo podemos aportar experiencias propias o ajenas que vienen delimitadas por contextos particulares y situaciones imprevistas. Necesitamos de las experiencias de otros, del valor de las mismas, de su disponibilidad para transmitirlas y de nuestra capacidad para asimilarlas y hacerlas nuestras. Todo lo cual constituye más un desiderátum que una realidad.

A un buen docente se le suponen competencias y determinadas cualidades, como empatía, honestidad, etc., pues debe transmitir valores, actitudes y ejemplos de vida con los que se identificaría un ciudadano crítico. Para ello debe conocerse mejor, conocer sus propias emociones, de modo que pueda conocer y reconocerse en los demás; y es ahí donde entra en juego la variedad de contenidos emocionales que se dan en la producción cinematográfica, pues en ella encontramos todas aquellas disposiciones emotivas en las que nos podemos ver reflejados. «El film no se puede considerar un universo cerrado, es una estructura dinámica, que propicia un diálogo entre el texto y el destinatario» (Gispert, 2009:74). El cine nos llega directamente porque nos vemos identificados con los protagonistas en diversidad de situaciones que hacemos nuestras y que además nos permiten reflexionar sobre nuestra forma de actuar. Gestionando adecuadamente las emociones que produce el cine se puede conseguir que los alumnos, mediante procesos de adaptación, adquieran una conciencia ciudadana que les permita canalizar de manera equilibrada sus propias emociones.

Sabemos que el buen docente no existe y tan solo nuestra profesionalización a lo largo de los años lograría acercarse a este ideal. De hecho, el ideal de la profesión docente se consigue a través de la reflexión educativa y crítica que debe estar basada en las experiencias sostenidas en las aulas con los alumnos; porque sin experiencias difícilmente podemos cuestionarnos nuestra actividad profesional, y difícilmente podríamos preguntarnos acerca de lo que se hace, el porqué, el para qué y el cómo.

Ya hemos apuntado otra cualidad que también formaría parte de lo que entendemos por un buen docente, y es la capacidad para desarrollar cierta empatía con la comunidad educativa (familias, alumnos, otros profesionales, etc.). Sin embargo esta cualidad no se genera espontáneamente y tampoco se encuentra ni en la formación inicial ni en el currículo del docente, sino que es preciso trabajarla para entendernos afectiva y cognitivamente con los demás; y para lo cual necesitamos el concurso de tiempo y vivencias, de experiencias emocionales y culturales, de tal modo que logremos identificarlas. 
La empatía debe adaptarse a la personalidad de cada persona, pero trabajarla en el corto periodo de la formación inicial del docente exige de una herramienta tan multifuncional como el cine, donde se reflejan la diversidad de emociones y culturas. Esta contradicción entre el tiempo y la demanda o la necesidad de esta cualidad, nos la puede resolver el cine con su enorme variedad de situaciones, personajes y contextos con los que nos podemos identificar en un momento determinado.

En cuanto a las competencias que debe sostener un docente, ya nos hablan numerosos manuales y diversos trabajos de pedagogía; sin embargo, de la honestidad como un modo de actuar que demuestre integridad de acuerdo a las normas sociales en las que se socializan los alumnos apenas encontramos referencias dando por sentado que es lo que se espera de todo buen docente. En su momento, Durkheim (1975:53) definió la educación como «la acción ejercida por las generaciones adultas sobre aquellas que todavía no han alcanzado un grado de madurez necesario para la vida social. Tiene por objeto suscitar y desarrollar en el niño un cierto número de estados físicos, intelectuales y morales que exigen de él tanto la sociedad política en su conjunto, como el medio específico al que está especialmente destinado». Sin embargo, la rectitud en las maneras de actuar no siempre nos identifica con los procesos de socialización. La diversidad de identidades culturales que se dan en la sociedad contemporánea choca en multitud de ocasiones con la homogeneidad que imponen unas normas comunitarias que son las que se transmiten en los procesos de socialización formales (Imbernon, 2001). En este sentido, el cine ofrece recursos al docente para la reflexión sobre la necesidad de obrar con honestidad, respetando las normas sociales y valores que permiten la convivencia en la diversidad al mostrar de manera significativa esta cuestión, mediante contextos y situaciones de gran variabilidad.

$\mathrm{Y}$ es que el cine no solo es arte. Es un documento sobre épocas, pensamientos, estilos de vida y costumbres. Un modo ideal para acceder a la sociedad y descubrir su realidad, ya que es reflejo de la vida misma y de la forma de comportarse en un momento determinado. Por su parte, sabemos que la Sociología como ciencia es una herramienta útil y práctica para comprender la realidad social. Es decir, conocer el comportamiento de las personas en grupo y para el grupo. En este sentido, nuestra empresa, como sociólogos de la educación, es analizar y conocer, desde una visión crítica, el sistema educativo y todas los protagonistas que lo forman (profesores, alumnos, familias y administraciones...) en relación a la estructura y el sentido de la sociedad en su conjunto.

Mediante la proyección de las películas sobre educación, pretendemos abrir nuevas sendas de reflexión que van más allá de las interpretaciones comúnmente aceptadas u oficialmente establecidas, dado que las cosas «no son lo que parecen». Pretendemos estudiar situaciones propuestas en diferentes películas sobre educación, o bien atender al análisis de fenómenos como son las desigualdades o los procesos de socialización, que son los que en este breve artículo pretendemos mostrar como ejemplos de prácticas curriculares en la formación inicial de los futuros docentes. Tan solo vamos a mostrar dos ejemplos de películas bien conocidas que sirven a nuestro propósito (Hoy empieza todo y El profesor Laz̧har). 


\section{Ficha técnica de la película Hoy empieza todo}

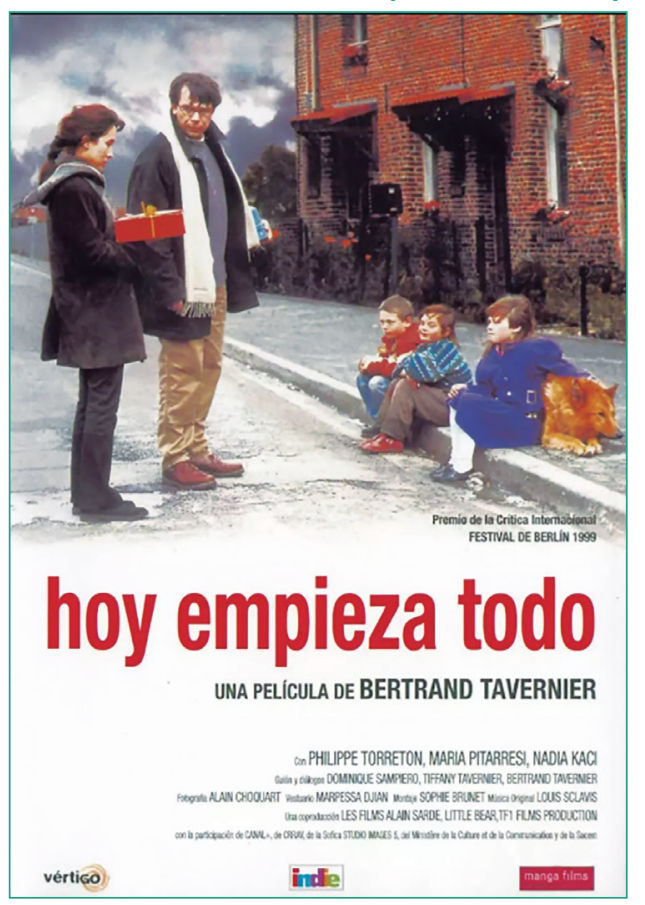

Título original: Ça commence aujourd'bui

Año: 1999

Duración: $107 \mathrm{~min}$.

País: Francia

Director: Bertrand Tavernier

Guión: Dominique Sampiero, Tiffany Tavernier, Bertrand Tavernier

Música: Louis Sclavis

Fotografía: Alain Cloquart

Reparto: Philippe Torreton, Maria Pitarresi, Nadia Kaci, Didier Bezace, Veronique Ataly, Nathalie Bécue, Emmanuelle Bercot, Françoise Bette

Productora: Les Films Alain Sarde/Little Bear/TF1 Films Production

Género: Drama|Enseñanza. Infancia

\subsection{Resumen}

Hoy empieza todo es una película que ofrece una clara visión de los problemas a los que se enfrenta la educación en zonas sin recursos económicos adecuados. El escenario de esta película es una escuela infantil de un pueblo minero situado en el norte de Francia, donde su protagonista Daniel Lefebvre, el director, tendrá que enfrentarse no solo a problemas que van más allá de la mera enseñanza, entrañando una problemática muy superior. La historia ocurre en el año 1998 cuando la crisis minera dejó a numerosas familias sin trabajo, lo que ocasiona una grave situación a padres y madres que perjudica la educación y el bienestar de sus hijos.

La escuela no dispone de los recursos suficientes como para atender a todos. Lefebvre y las demás maestras se tienen que hacer cargo de un gran número de alumnos por aula y, además, deben hacer frente a los problemas de los niños a consecuencia de la situación económica de sus padres. Debido a los escasos recursos que aportan los servicios sociales, el trabajo de Daniel Lefebvre como director y maestro es complicado. No solamente se encarga de la educación de sus alumnos, sino que también intenta ayudarles así como a sus familias. En otras palabras, en muchas ocasiones debe ir más allá del cargo de director y asumir un rol de trabajador social. Tanto compromiso e implicación hace que la desesperación le domine en ciertas ocasiones.

Algunas de las circunstancias a las que se enfrentará durante la trama desembocarán en tragedia, lo que hará que las dudas lleguen a él, valorando las opciones de seguir colaborando en ayudar a las familias o dejar el trabajo al verse tan desbordado.

\subsection{Comentarios}

El espectador puede hacerse múltiples preguntas en cuanto acaba el filme, pero lo que más llama a la reflexión es cuando nos preguntamos sobre cómo perciben la realidad que les tocó vivir esos niños de cinco años. La escuela es su patio de recreo, van a la escuela aunque tengan fiebre porque las madres quieren dejarlos allí buena parte del día con el fin de que se olviden de la realidad que viven en sus casas. 
Aunque muchos de los niños van a la escuela en muy malas condiciones, ellos siguen cantando y jugando en el patio, escapando momentáneamente de la pobreza y del sufrimiento que hay en sus entornos familiares. La grave situación que viven esas familias, no solamente influye en la alimentación de los niños, sino que también tiene consecuencias en lo psicológico como, por ejemplo, Laetitia, que debe utilizar una linterna para poder caminar por su casa, tiene que dormir con abrigo, gorro y bufanda durante el frío del invierno, y está condenada a sufrir viendo cómo su madre se refugia en el alcohol. Cabe destacar el momento en que una ebria señora Henry sale corriendo de la escuela, dejando allí a sus dos hijos. La reacción de la niña llama poderosamente la atención, pues su actitud hace ver que entiende todo y nada al mismo tiempo, como si no le hubiera extrañado la forma de actuar de su madre, pero también queriendo eludir lo que había pasado. Sin embargo, en la escuela sonríe y parece feliz, enmascarando su realidad cotidiana dentro de esos muros.

Por otro lado, el caso de Jimmy es algo más complicado que el de Laetitia, ya que la situación que vive en su hogar hace que su sufrimiento sea externo además de interno. Es decir, este niño debe someterse a duros maltratos físicos por parte de su tío, que parece pagar su pobreza y sus fracasos con violencia contra su propio sobrino.

La situación social y económica que vive ese pueblo minero llega hasta tal punto que la escuela de Daniel Lefebvre sufre un robo durante una noche. Este momento del filme es importante para darse cuenta de lo mal que lo está pasando la gente de ese pueblo como para robar en una escuela de párvulos y dejarla destrozada. Los autores de dicho saqueo son dos niños que parecen entrar en la adolescencia, algo muy importante a tener en cuenta, pues ellos simbolizan toda una generación que ha perdido cualquier tipo de aspiración en sus vidas, tomando caminos de tal forma que su futuro puede acabar llevándolos a la cárcel en lugar de saber lo que es un oficio.

Al final de la película se ve cómo los niños juegan felices en el patio bajo la presencia de todos los padres y profesores. Después del trágico suicidio de la señora Henry junto a Laetitia y su otro hijo, después de que la policía alejara a Jimmy de su familia, después de todo un curso lleno de contratiempos, problemas y desgracias, vemos como la vida continúa para todos. A pesar de que muchas de esas familias estén en peligro de pobreza extrema, también consiguen darse cuenta de que las alegrías llegan estando los unos con los otros, haciendo ver al espectador que la felicidad es más palpable cuando uno se aleja de la realidad material y disfruta con su comunidad.

Hay cosas que nunca desaparecerán, están en la carne y hablan. Están en la tierra. Montones de piedras apiladas una a una con las manos del padre, del abuelo. Toda su paciencia acumulada resistió la lluvia, al horizonte haciendo pequeños montoncitos ante la noche.

Para retener la luz de la luna, para estar erguidos contaremos a nuestros hijos, les diremos que fue duro pero que nuestros padres fueron unos señores y que heredamos eso de ellos: montones de piedras y el coraje de levantarlas.

Con la lectura de este texto termina la película, síntesis perfecta y muy bien adaptada al mensaje que se puede entrever en la obra, donde aun aconteciendo situaciones que desbordan siempre encontramos un espíritu de esperanza y de mejora tanto por los que se quedaron en el camino como por los que continúan en él. 


\subsection{Aspectos sobre la desigualdad}

La película se desarrolla aproximadamente durante un curso académico, en el cual los maestros y maestras se ven perjudicados por los numerosos problemas que tienen las diferentes familias de los niños. Por tanto, a lo largo de la película se abordan temas como niños mal alimentados, situaciones infrahumanas en el hogar, falta de recursos para abonar las primas de la escuela, todos estos pertenecen a un mismo problema la falta de recursos económicos, ofreciendo una clara diferencia entre una escuela situada en una zona privilegiada y esta situada en una zona marginal.

\subsection{Socialización y enseñanza de normas sociales a los alumnos}

El entorno donde se desarrolla una persona va a influenciar en su manera de socializarse y la dimensión de las normas sociales va a variar notablemente. El ámbito donde se desarrolló esta película muestra un ámbito de socialización en un entorno marginal donde las normas sociales se ven franqueadas con asiduidad, pero también sobresalen valores como cooperación.

\section{Ficha Técnica de la película El profesor Lazhar}

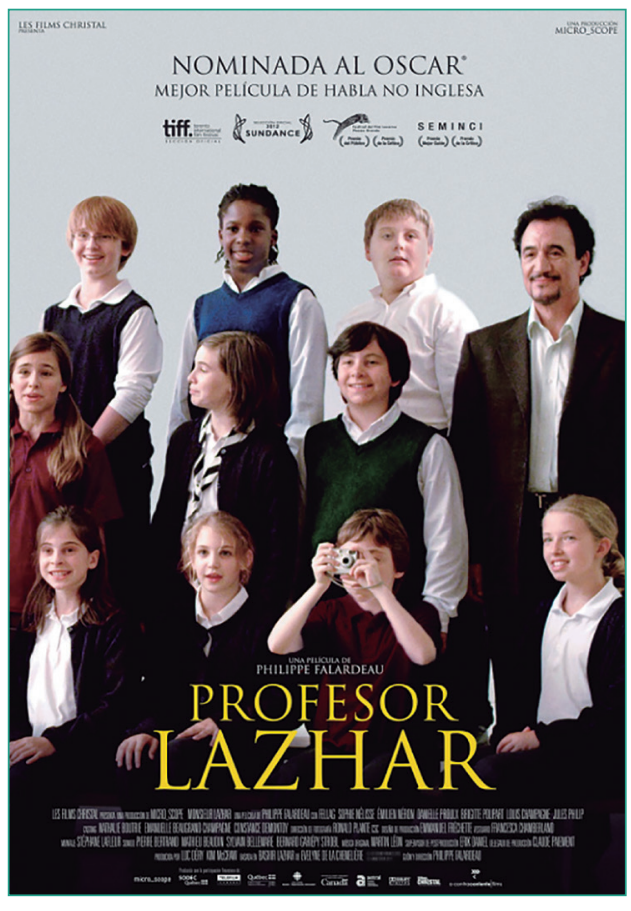

\subsection{Resumen}

El Profesor Laz̧har trata sobre un aula de educación primaria en un colegio de Montreal (Canadá) que vive una gran tragedia. Su profesora se suicida colgándose del techo del aula. Uno de los alumnos, Simon, que a su vez es el niño más rebelde y problemático de la clase, la encuentra y pide ayuda al resto de los docentes. Éstos intentan que ningún otro niño vea a su maestra de esta manera, pero a pesar de los esfuerzos, Alice, la protagonista por excelencia de esta película, también la ve.

Este suceso hace que la directora de la escuela busque rápidamente un sustituto, que recae en la figura de Bachir Lazhar, un argelino de 55 años. Sin embargo este hombre esconde un secreto, él no es maestro ni ha impartido clase en Argelia como hace entender a la directora de la escuela, sino que es 
un camarero que ha tenido que huir de Argelia cuando su mujer fue amenazada de muerte por escribir un libro en contra del gobierno.

Desgraciadamente no toda la familia de Bachir corrió la misma suerte que él, ya que mientras él huyó a Canadá para prepararlo todo y así poder recibir a su familia, su mujer y sus hijos sufrieron un atentado y murieron. Sin embargo Bachir Lazhar no solo tiene que lidiar con ese terrible dolor, sino que ahora deberá enfrentarse a una clase de niños traumatizados por la muerte de su profesora.

Desde el primer momento podemos observar en la particularidad de la forma de enseñar de Bachir las grandes diferencias que tiene respecto a la anterior profesora aunque en definitiva va ganándose la confianza de todo el mundo que le rodea, profesores y alumnos, gracias a su sinceridad y a su forma de afrontar los problemas.

\subsection{Comentarios}

Esta película muestra diversas caras de la vida actual, tanto la de la educación (en este caso la de Canadá), como la del dolor psicológico infantil ante un suceso tan dramático. Es crítica con el sistema educativo al observar un sistema burocrático, cuyo objetivo es de carácter económico y mercantil, y donde el docente se muestra más como un trabajador asalariado que vocacional.

Se señalan dos opciones posibles de cómo llevar la enseñanza. O bien seguir unos reglamentos y leyes educativas con el fin de educar a los alumnos sin emociones y solo usando unos cánones estandarizados, o bien ayudar al alumno a aprender e intentar que comprenda los conceptos no solo de las asignaturas, sino también de los diversos aspectos emocionales de la vida. El profesor Laz̧har, por supuesto, opta por la segunda opción, ya que no comprende que en Canadá se prohíba cualquier gesto de cariño o de regañina hacia un alumno. Vemos un colectivo de profesores que solo se dedican a impartir clase estrictamente, dentro de un marco políticamente correcto, a pesar de que ellos saben que darían mucho más de su parte si dispusieran de libertad para hacerlo.

También critica la pérdida de poder que han tenido los profesores frente al alumno, además de mostrarnos a algunos niños como fieles reflejos de la identidad de sus padres y no como personas que construyen su personalidad por sí mismos.

Por otro lado, esta película no solo nos muestra aspectos educativos, sino que profundiza también en los sentimientos de los alumnos y de los distintos personajes ante una situación tan dramática. Por su parte, las autoridades escolares prefieren abordar este tema de una manera muy delicada y no tratarla abiertamente dejando que los niños se expresen libremente de modo que puedan sacar el dolor que les abruma. Finalmente entendemos que lo adecuado era explicar y tratar la situación con normalidad, ya que a pesar de que los niños siguen siendo ingenuos e inocentes, son capaces de comprender algunas cosas.

\subsection{Aspectos sobre la desigualdad}

Las desigualdades más visibles son los diversos grados de madurez de los distintos alumnos de una misma edad y cómo afronta cada uno el trauma de la muerte de su profesora. Entre los alumnos del profesor Lazhar se encuentran todo tipo de estudiantes, entre ellos un estudiante musulmán, otro de origen chileno y alumnos afroamericanos. Sin embargo, éstos no son los alumnos que más peso cobran a lo largo de la historia. La poca importancia que se les puede llegar a dar muestra que, en realidad, están muy bien integrados con el resto de sus compañeros. De hecho, no hay ningún tipo de 
rechazo por parte de los alumnos nativos hacia éstos. Incluso en una de las escenas de la película, hacia el final de ésta, se ve a una niña musulmana llevando el velo y a una chica canadiense que se acerca a ella para comentarle que llevan las mismas zapatillas. Ambas niñas se ríen y empiezan a jugar juntas. Por lo tanto, una vez más se observa una aceptación total más que una discriminación.

Se podría decir que la desigualdad es mucho más visible en los profesores, pero esta afirmación se debe observar con mucha cautela. Es cierto que hay profesores extranjeros, como la maestra con la que Lazhar parece comenzar una relación sentimental. Cuando ella le invita a cenar le confiesa que es inmigrante, ya que ha vivido y trabajado durante bastantes años en países de otro continente. No obstante, su condición de inmigrante no provoca un rechazo por parte de la sociedad o del centro, sino que ella la utiliza para complementar de manera positiva los contenidos que debe enseñar.

Igualmente, se detectaría un aspecto de desigualdad en una escena en que los alumnos llegan a decir que nunca habrá justicia entre ellos y los profesores, ya que las ideas de estos últimos son automáticamente consideradas como las correctas, y nunca van a poder ser cuestionadas. Esta desigualdad se hace más evidente y grave cuando prohíben a los alumnos hablar sobre el suicidio de su maestra fuera de las sesiones con la psicóloga del colegio. Es un tema que se reduce a unas pocas horas en las que se intenta que superen el trauma, aunque escondiéndolo y enterrándolo para el resto de las clases y de los alumnos del colegio.

Sin embargo, es en Lazhar en quien se observa una mayor desigualdad al tener que superar una serie de obstáculos fruto de las diferencias existentes entre Canadá y Argelia. Esas diferencias le provocan una serie de llamadas de atención por parte de los miembros del profesorado y de los padres de ciertos alumnos. Por un lado, el profesorado impone, en cierto modo, los materiales que el profesor Lazhar debe usar en sus clases. Además, le prohíben cualquier tipo de contacto físico con los alumnos y le obligan a no hablar del suicidio de la maestra con los estudiantes. Por otro lado, los padres de ciertos alumnos también muestran algunas de sus quejas hacia el profesor, pues éste parece dispuesto a educar íntegramente a sus alumnos, y los familiares insisten en que se debe limitar a enseñarles conceptos, y no a educarlos. Curiosamente, también los propios alumnos realizan alguna llamada de atención al profesor argelino. Mientras que Alice le recomienda unos libros más adecuados al nivel de los alumnos, otra de las alumnas corrige uno de los conceptos que Lazhar utiliza para referirse a un elemento de la frase, llegando incluso a ridiculizarlo por estar demasiado desfasado y muy acostumbrado a la educación argelina. De hecho, aunque Lazhar parece conseguir integrarse finalmente con los alumnos, es despedido.

\subsection{Socialización y enseñanza de normas sociales a los alumnos}

La película El profesor Lazhar nos presenta un aula en la que el suicidio de la profesora, un acontecimiento desagradable e inesperado, causa un ambiente enrarecido en la escuela, que deja a sus alumnos en autentico shock. Es en este contexto en el que se produce la llegada del profesor Lazhar, un docente sin experiencia educativa, el cual se valdrá únicamente de su intuición para llevar a cabo sus clases. La película muestra las relaciones de Lazhar con sus alumnos, jugando éstas un papel esencial en el aprendizaje. Como docente Lazhar ayuda a sus alumnos a superar las dificultades, especialmente emocionales provocadas por la muerte de su profesora. A lo largo de la película vemos en los alumnos diferentes ritmos de superar la muerte de la profesora, dependiendo de su capacidad de asimilación del 
suceso, así como de su unión y relación con la misma. Claro ejemplo de esta circunstancia es Simon, quien se siente culpable por la muerte de la profesora.

Bajo este contexto la película, muestra otra realidad que no es otra que el tratamiento de los niños en la escuela ante un suceso de tal magnitud. De esta manera el profesor Lazhar, nos hace reflexionar sobre si hay que tratarlos como «niños» y sobreprotegerlos y aislarlos del acontecimiento, evitando el tratamiento del tema en el aula, tal y como llevan a cabo las autoridades educativas y padres, o por el contrario tratarlos como personas, que a pesar de su ingenuidad son capaces de asimilar, tratar y afrontar el suceso con normalidad. En base a la película esta segunda opción es la que más efecto provoca en los alumnos cuando Lazhar, trata el tema en el aula con normalidad y sinceridad, ayudando a alumnos como Simon. De esta manera el profesor, debe actuar también como una especie de psicólogo en el aula, percatándose de las emociones y sentimientos de sus alumnos, siempre apoyado por el departamento de orientación y pedagógico, y no de manera independiente.

De manera menos marcada, la película muestra otra serie de realidades, como la relación entre adultos y niños, reflejada no solo en la relación entre docentes y alumnos, sino también entre padres e hijos. Así mismo se muestra igualmente el tema de la inmigración, reflejado en la escena de la tutoría que tiene Lazhar con los padres de una alumna, que le achacan su procedencia extranjera, circunstancia que a ninguno de los alumnos parece importar, y que hoy en día debido a la globalización existente en el mundo es del todo irrelevante.

\section{Conclusiones: el cine en la formación del docente}

Como se desprende de estos dos ejemplos audiovisuales, la percepción de una realidad posible y la identificación con los protagonistas, permite al futuro docente, a través de un análisis reflexivo, adoptar un gran número de posiciones respecto a situaciones que, de ser posibles en su biografía profesional, resolvería sin excesivas dificultades, toda vez que ya fueron debatidas, analizadas y adoptadas en el marco de su formación. Vivimos un momento de globalización de la cultura mediática que está generando nuevas formas de construcción de identidades y ciudadanía, aproximando las diferentes culturas y comunidades, por lo que la incorporación del cine como una herramienta más de las Tecnologías de la Información y la Comunicación (TIC) en los grados y máster de formación de maestros y profesorado de secundaria, constituye un elemento fundamental en el desarrollo y potenciación del futuro docente, al menos mientras las prácticas sigan siendo tan insuficientes como en la actualidad.

\section{Referencias bibliográficas}

Beltrán Llavador, José (2006): “Sobre cine, sociedad y educación: Cómo hacer cosas con imágenes”. Revista de Ciencias Sociales, 23, 88-99.

Durkheim, Émile (1975). Educación y sociedad. Barcelona: Península.

Gispert Pellicer, Esther (2009). Cine, ficción y educación. Barcelona: Laertes.

Imbernón, Francesc (2001): "Claves para una nueva formación del profesorado". Investigación en la escuela, 43, 57-66 


\section{Nota biográfica}

Joaquín Giró Miranda es profesor Titular Sociología del Departamento de Ciencias Humanas de la Universidad de La Rioja, donde imparte las materias de sociología de la educación en el Máster de Profesorado de Secundaria y en el Grado de Maestro Primaria. Doctor por la Universidad de La Rioja (UR) y licenciado en Ciencias Políticas y Sociología por la Universidad Complutense, ha sido Secretario de la Asociación de Sociología de la Educación (ASE), y del Comité de Investigación 13 (Sociología de la Educación), en la Federación Española de Sociología. Autor de trece libros y coordinador de nueve publicaciones; ha publicado más de veinte artículos en revistas científicas y ha colaborado en treinta y siete obras colectivas. En la actualidad lleva dos líneas de investigación: Sociología de la Educación y Sociología de las Migraciones. 